\title{
Voltage Sag Region Study in Distributed Power Supply
}

\author{
Lu Xining ${ }^{1}$, Liu Hao ${ }^{2}, \mathrm{He} \mathrm{Kai}^{1}$, Xu Qing ${ }^{1}$, Chen Xiaolin ${ }^{1}$ \\ 1.State Grid Jibei Electric Power Co. Ltd.,Langfang power supply company, dispatching and \\ control center, Langfang, Hebei, 065000, China

\begin{abstract}
2.Training department teaching security,China people's Armed Police College, Langfang, Hebei, 065000, China
\end{abstract}

Keywords: Voltage Sag; Distributed Power Supply; Sag Region; Photovoltaic Plant.

\begin{abstract}
This paper established two types of models of distributed power supply in PSCAD/EMTDC and connected these two power supplies in the power distribution networks with 18 nodes to simulate respectively under specified voltage control and specified power factor strategies. Then, the simulated data was loaded into Matlab to analyze and calculate. It can be concluded that the shorter the distance between the interconnected of photovoltaic plant and the sensitive points, the more significant compensation effect of voltage sag, the amplitude of the voltage sag went down with the temperature increase and went up with the illumination intensity increase. When the threshold value of the voltage sag's $70 \%$ was obtained under specified voltage at the sag region and power factor control strategies based on root mean square value method, the connection of photovoltaic plant can effectively slow down the severity of the voltage sag, which makes the possibility of the influence of power distribution network on sensitive equipment largely go down. The bigger the capacity of the photovoltaic cell, the shorter distance between interconnected location and sensitive load, the smaller the sag depth at sensitive load locations, as well as the shorter the duration time of the sag.
\end{abstract}

\section{Introduction}

Sag region means the occurred malfunction causing voltage sag in electricity system, which is the region of the trouble points making the concerned sensitive load can work normally1, 2 ]. Voltage sag region analysis is the precondition of the comprehensive evaluation of the voltage sag, and the history of the failures in the sag region can be utilized to evaluate the expected times of the users' equipment annual voltage sag and economic loss of the voltage sag. In the meanwhile, for user, sag region can be used as the judgment condition of whether sensitive equipment occurs voltage sag event and the basis of selecting sensitive (important) equipment factory site under failure condition; for power system, sag region can be used to select proper operation mode by auxiliary service decision system dispatcher under the condition of meeting power system PTD proper deployment, in order to relief the occurrence of users' the voltage sag events, so as to realize the dynamic safety protection of the power system and reliable high quality economy operation, which offers essential data basis for the power system design, plan and reconstruction [3-5] .

Based on the connected power system theoretical analysis of the distributed power supply, this paper selected synchronous wind turbine generator of the synchronous interface as research object, established the simulated model of synchronous wind turbine generator in PSCAD/EMTDC, connected into medium voltage distribution network with 18 nodes, conducted simulation work under specified voltage and power control strategies, analyzed and calculated the data that was imported into Matlab, studied the influence of the voltage at connecting point on voltage sag region respectively under specified voltage strategy, as well as the influence of power factor on voltage sag under specified power strategy. 


\section{Voltage sag region analysis and distributed power supply}

\subsection{Voltage sag region}

The so called sag region means the occured failure in the system causing voltage sag, and the sensitive load in the concerned one point cannot meet the failure point in normal working region. It directly reflects the voltage sag issue caused by short-circuit fault. The voltage sag caused by the failure in the the sag region will make the concerned sensitive laod cannot work normally, however, the failure occured outside of the sag region will not influence the normal working of the sensitive load[4]. Currently, there are two main types of voltage sag analysis mehtods, namely failure point method and critical distance method.

Assume to install voltage sag monitoring decvice in the No.i system node with $\mathrm{N}$ nodes, set threshold voltage of this monitoring device is $p$, then the actuall voltage of this threshold voltage is close voltage in the sag region of No.i node. Failure at node $f$ will certainly results in voltage reduction at node $i$. If failure makes the volate ampitude at node $i$ lower than $p$, then node f locates at the sag region of node $i$, if people mark the nodes in the sag region of node $i$ as 1 and the nodes outside of teh sag region as 0 , when people take the failure point $f$ in the whole network, it can be concluded that the sag region matrix of $i$ node as the following types.

$$
M_{p(i, j)}=\left\{\begin{array}{ll}
1 & \forall_{i j} \leq p \\
0 & \forall_{i j}>p
\end{array} \quad \forall_{\mathrm{ij}} \in(1 \ldots N)\right.
$$

Where, the element value of $\mathrm{Mp}$ can only be 1 or $0, \mathrm{Mp}(\mathrm{i}, \mathrm{j})=1$ represents when the voltage of sag region set as $p$, the occured at node $j$ will lead to the voltage at node $i$ lower than the threshold value $p$ of monitoring device. $\operatorname{Mp}(i, j)=0$ represents the occured failure at node $j$ will not cause the voltage at node i lower than threshold value.

\subsection{Distributed power supply}

Distributed power supply means that it is designed and installed at user's location or surrounding small generator set which is flexible and independent, in order to support the existed the economic running with power distribution network and meet the demands of special users, the power grades normally range from dozens of KW to dozens of MW. Distributed power supply network interfaces normally have three types including synchronous generator type, power electronic equipment and asynchronous generator type. The typical capacity socope and its network interfaces of each type of distributed power supply are shown as table 1.

Table 1 DG capacity and its network connecting types

\begin{tabular}{ccc}
\hline $\begin{array}{c}\text { Electricity generation } \\
\text { way }\end{array}$ & Capacity scope & Connecting way \\
\hline $\begin{array}{c}\text { Solar photovoltaic } \\
\text { Wind }\end{array}$ & $\mathrm{W}-\mathrm{kW}$ & $\begin{array}{c}\text { Power electronic equipment } \\
\text { W-MW }\end{array}$ \\
$\begin{array}{c}\text { Fuel-cell power and } \\
\text { battery }\end{array}$ & $\mathrm{kW} \sim \mathrm{MW}$ & $\begin{array}{c}\text { Power electronic equipment, synchronization } \\
\text { generator, asynchronous generator } \\
\text { Power electronic equipment }\end{array}$ \\
$\begin{array}{c}\text { Micro gas turbine } \\
\text { Ocean power }\end{array}$ & $\mathrm{kW} \sim \mathrm{MW}$ & $\begin{array}{c}\text { Power electronic equipment } \\
\text { synchronization generator }\end{array}$ \\
\hline
\end{tabular}

This paper studies through solar photovoltaic electronic generation and fuel-cell power and battery electronic generation can generate direct current in the distributed power supply of the power electronic equipment connecting network, which needs to pass voltage source inverter till to connect network, wind electronic generation normally uses alternating current-direct currentalternating current connecting way to convert the generated alternating current to direct current, 
which then needs to pass inverter till to power freqency alternating current connected in the network, as well as micro gas turbine electronic generation is high frequency alternating current, which needs to pass $\mathrm{AC} / \mathrm{Ac}$ or $\mathrm{AC} / \mathrm{DC} / \mathrm{AC}$ to complete frequency conversion to connect in the network. The distributed power supply through inverter to connect in the network, and the principle graph is shown in photo 1 .

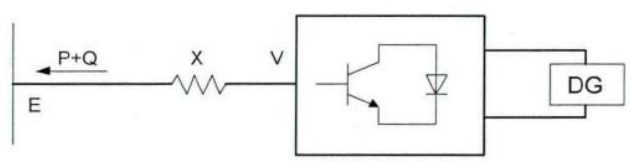

Photo 1 Distributed power supply pass the inverter to connect in the network and its principle graph

Assum the output voltage of the distributed power supply is $\mathrm{V}$, the voltage of the power distribution network is $\mathrm{E}$, the output active power and reactive power are $\mathrm{P}$ and $\mathrm{Q}, \mathrm{X}$ represents equivalent reactance of the transformer, the power angle is $\xi$, the following can be obtained:

$$
\begin{gathered}
P=V E \sin \xi / X \\
Q=(V E \cos \xi / X)-E^{2} / X
\end{gathered}
$$

Shown as photo 2, specified voltage control (PV control), namely distributed power supply participate system voltage adjustment, the output active power and the voltage at the connected point keep the same.

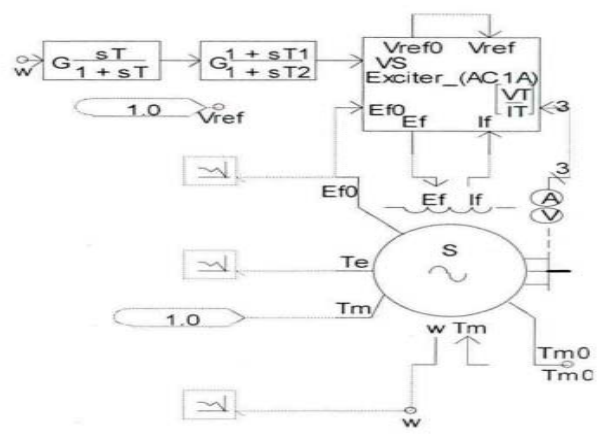

Photo 2 Simulated model of the synchronization type distributed power supply

The distributed power supply of the power electronic equipment connected network uses sinusoida pulse modulation (SPWM) to control the generated driving signal, the control diagram is shown in photo $3, \mathrm{M}$ and $\varepsilon$ represent amplitude and phase position of modulation sine wave in the SPWM control process respectively.

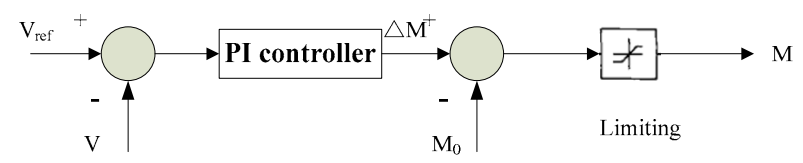

Photo 3 Control system graph of the inverter type DG

\section{Photovoltaic power station contained power distribution network voltage sag region analysis}

\subsection{Model of photovoltaic array}

Photovoltaic array is the source of photovoltaic power station energy and the most basic element of the photovoltaic power station. It utilizes photovoltaic effect of the semiconductor materials completing the conversion from luminous energy to electric energy. Photovoltaic battery can be divided into silicon type photovoltaic battery, non-silicon type semiconductor photovoltaic battery, organic photovoltaic batter and so on according to various materials. Iph is photo-generated current with its value having the property of direct ratio to radiation intensity of the incident light of photovoltaic battery and the area of the photovoltaic battery. With the temperature going up, the value has corresponding increase slightly. $U$ is the open-circuit voltage of the photovoltaic battery, and its value has the property of direct ratio to the logarithm of incident light of the radiation intensity, but is inversely proportional to the environment temperature, and no relationship with the 
area of the battery. When it is dark current without light illumination, the external voltage of the photovoltaic battery is just close to P-N node, the single-phase current generated inside of the P-N node and having the opposite direction with light current, which is equivalent to dark current.

$$
\begin{gathered}
I=I_{p h}-I_{o}\left[\exp \left(\frac{U+I R_{s}}{A U_{T}}\right)-1\right] \\
U_{T}=m(K T / q) \\
I_{p h}=I_{s c} \frac{G}{G_{r e f}}\left[1+\alpha_{T}\left(T-T_{r e f}\right)\right] \\
I_{o}=I_{R S}\left(\frac{T}{T_{r e f}}\right)^{3} \exp \left[q E_{g}\left(\frac{1}{T_{r e f}}-\frac{1}{T}\right) / K A\right] \\
I_{R S}=I_{S C} /\left[\exp \left(\frac{U_{o c}}{A V_{T}}\right)-1\right]
\end{gathered}
$$

The standard test condition includes temperatre $\operatorname{Tref}=25^{\circ} \mathrm{C}$, illumination intensity $\mathrm{Gref}=1000$ $=\mathrm{W} / \mathrm{m} 2$, UOC us tge ioeb-circuit voltage under the standard condition. ISC is the short circuit current under standard condition. I is battery output current; $G$ is illumination intensity; $m$ represents the sequent photovoltaic battery quantity in photovltaic module; A represents ideal constant of diode; a $\mathrm{T}$ is short circuit current temperature factor; Eg represents energy gap; Rs is series resistance; boltzmann's constant $\mathrm{k}=1.386 \mathrm{e}-23 \mathrm{~J} / \mathrm{T}$; Kulun constant $\mathrm{q}=1.6 \mathrm{e}-19 \mathrm{C}$.

Multiple photovoltaic module installs in series to construct photovoltaic array, which can offer bigger transmission power to system. In actual application, the photovoltaic array is consisted by $\mathrm{Np}$ modules to in parallel connection and Io modules to series connection, and the output current is as the followings:

$$
I=N_{p} I_{p h}-N_{p} I_{o}\left[\exp \left(\frac{U+I R_{s}}{A N_{\mathrm{S}} U_{T}}\right)-1\right]
$$

When the connected load RL of the photovoltaic battery ranging from 0 to infinitely great, the range of the photovoltaic battery output voltage $\mathrm{U}$ is 0 to UC. The output current is between 0 to IC, the output I-U curve of the photovoltaic battery can be obtained according to that, namely the voltampere characteristics curve, which is shown in photo 4.

It can be seen from photo 4, when the output voltage value is smaller, the output current of the photovoltaic battery basically will not change with the continous change in voltage, the photovoltaic battery can be equivalent to constant current source at this time. When output voltage over a certain limit value, the tiny voltage change will make current have quick response, the photovoltaic can be equivalent to a constant voltage source at this time. Therefore, the output property of the photovoltaic battery has typical nonlinearity property. Under a certain illumination intensity and temperature, the output voltage and current of the photovoltaic battery will shift on the same curve, and the output power will change with its changes.

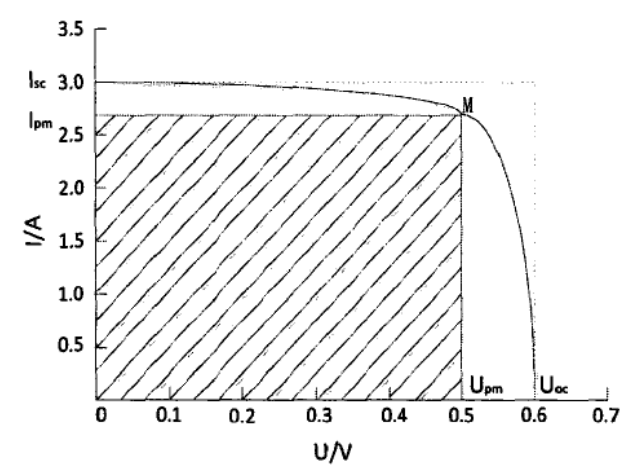

Photo 4 I-U curve of the photovoltaic module 


\subsection{Trace and control of the biggest power}

Temperature and sunlight intensity has bigger influence on short circuit and open circuit of the photovoltaic array, the system needs to guarantee photovoltaic array to realize biggest power output under the condition of the current sunlight temperature, in order to get stable working points, and the photovoltaic array must realize biggest power points to trace and control.

The working flow of the biggest power control is shown in photo 5: firstly, it monitors the output voltage and current of the current photovoltaic array to get the current output power of array, it then compares with the memorized power, and it repeats such work continuously, which makes photovoltaic array keep working in the biggest power points all the time.

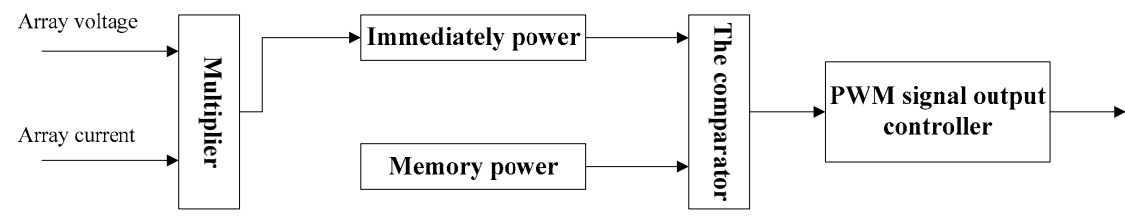

Photo 5 Working flow block diagram of the MPPT

This paper uses admittance incremental method to realize such control. Such method uses the characteristic of the slope is 0 at the biggest value point of the $P \sim U$ curve of the photovoltaic array, and it also uses the method to get the extremal to the first derivative to get the derivation of the $\mathrm{P}$, it can be drawn that:

$$
\begin{gathered}
\frac{d P}{d U}=I+U \frac{d I}{d U}=0 \\
U \frac{d I}{d U}=-\frac{I}{U}
\end{gathered}
$$

Formula (11) is the photovoltaic array getting the condition of biggest power point, namely, when the variation of the output conductivity is equal to the negative value of the output conductivity, the photovoltaic array works at the biggest power point. Such method has higher controlling accuracy and faster response speed, therefore, it is widely used. Photo 6 shows its control flow diagram. In this method, the output voltage of the photovoltaic array can trace the variation of the illumination intensity and temperature stably, the power loss at the biggest power point is small and the vibration amplitude is smaller.

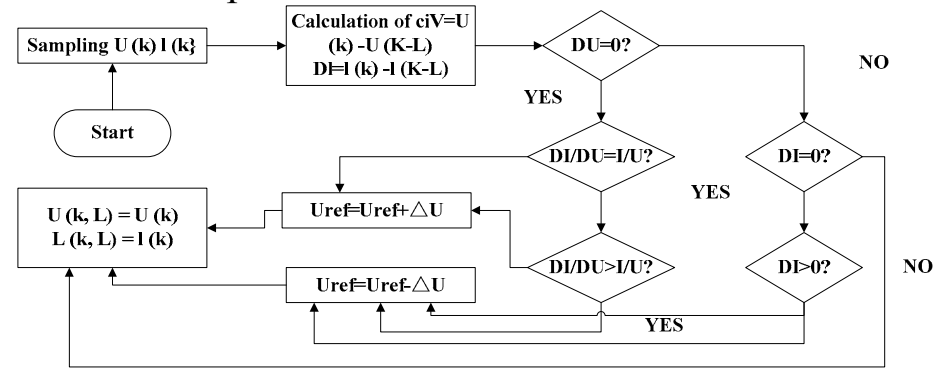

Photo 6 Control flow diagram of the admittance of the incremental method

\subsection{Inverter model}

Inverter connected network is generally alternating voltage source, the output side also has two ways of voltage control and current control when inverter and network connected operation. When using voltage control, voltage source and voltage source connected operation will occur, it is easy to occur circulation condition at this time, which is not good for network, therefore, current control method is used generally, it only needs to guarantee the output current of the inverter can trace network voltage with its simple control method. In conclusion, the control strategy of the photovoltaic network inverter generally uses voltage input and current source output ways. Specific to voltage source control way, we usually use fixed switching frequency controlling method, photo 7 shows the control diagram of such method. 


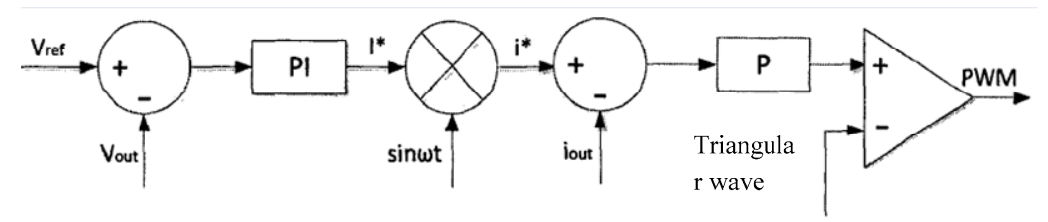

Photo 7 Diagram of the fixed switching frequency controlling method

It is seen that the reference current value is generated by the differential value between reference voltage and the output voltage of the inverter, and the magnified value of differential value between the output actual current value of the inverter and the reference current value meets with the triangular value to control the cut-off of the controlling inverter switch. The fixed working frequency under such method is the frequency of the triangle carrier wave. As such controlling way has fixed frequency and the harmonic wave generated by inverter is also relatively fixed, so the design of the filter circuit also becomes relatively simpler. From the analysis, it can be concluded that such way is appropriate to grid-connected photovoltaic power station system.

\section{Experiment simulation and verification}

Combine each module of the above photovoltaic power in PSCAD/EMTDC and the simulation of the connected the photovoltaic power in node 18 power distribution network, the electric sizes of the used solar photovoltaic battery components is shown table 2. Photovoltaic array is connected in network by $0.4 \mathrm{kV} / 10 \mathrm{kV}$ potential transformer with the capacity of $1.25 \mathrm{MVA}$ by using the connection way of $\mathrm{D}$,ynll.

Table 2 Photovoltaic array parameters

\begin{tabular}{ccccccccc}
\hline $\begin{array}{c}\text { Parameter } \\
\text { name }\end{array}$ & $\begin{array}{c}\text { Reference } \\
\text { illumination } \\
\text { intensity }\end{array}$ & $\begin{array}{c}\text { Reference } \\
\text { temperature }\end{array}$ & $\begin{array}{c}\text { Open- } \\
\text { circuit } \\
\text { voltage }\end{array}$ & $\begin{array}{c}\text { Short- } \\
\text { circuit } \\
\text { current }\end{array}$ & $\begin{array}{c}\text { Voltage } \\
\text { at } \\
\text { biggest } \\
\text { power } \\
\text { point }\end{array}$ & $\begin{array}{c}\text { Current } \\
\text { at } \\
\text { biggest } \\
\text { power } \\
\text { point }\end{array}$ & $\begin{array}{c}\text { Series of } \\
\text { battery } \\
\text { quantity of } \\
\text { the } \\
\text { photovoltaic } \\
\text { array }\end{array}$ & $\begin{array}{c}\text { Battery } \\
\text { quantity in } \\
\text { parallel of } \\
\text { the } \\
\text { phovoltaic } \\
\text { array }\end{array}$ \\
\hline Value & 1000 & 25 & 21.7 & 3.35 & 17.4 & 3.05 & 40 & 20
\end{tabular}

Assume that single-phase ground metal failure occurs in node 15 in the system, photo 8 gives the voltage sag amplitude value at sensitive load node 7 connected by ABCD 4 connection ways respectively in the photovoltaic power station under the PV controlling strategy, where, photo (a) studies the influence of temperature on voltage sag amplitude when the illumination intensity is specified, the illumination intensity is $1000 \mathrm{~W} / \mathrm{m} 2$ in the system at this time with temperature range from $20^{\circ} \mathrm{C}$ to $30^{\circ} \mathrm{C}$. The voltage sag amplitude gradually reduces with the temperature going up. This is because the short-circuit current of the photovoltaic array has slight increase when the temperature increases, however, the short-circuit voltage goes down dramatically resulting in output power reduce, and the voltage at the biggest power point of the photovoltaic array also goes down at the same time, the power going to system also becomes small when the failure occurs.

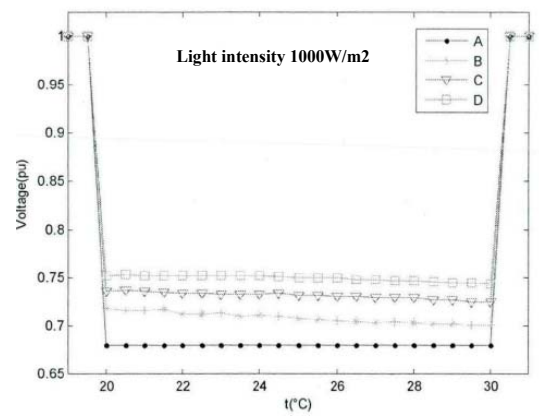

Photo 8 Voltage sag amplitude

The corresponding sag region can be obtained by connecting the $70 \%$ threshold value corresponded critical failed points. Photo 9-12 offers the power distribution network sag region of 
the corresponded 4 draught fan connection ways at this threshold value under 4 failed types. It can be seen that the caused voltage sag for the three phase ground failures in the power distribution network is most serious. Specific to all the failed types, photovoltaic power station connection makes the voltage sag region reduce. When power distribution network occurring failures, the sag region of the connected several equivalent capacity's the photovoltaic power station at different connection nodes is smaller than the photovoltaic power station connected with equivalent capacity at only one node. The sag region scope is reduced when the photovoltaic power station is connected in the sensitive node 7 network.
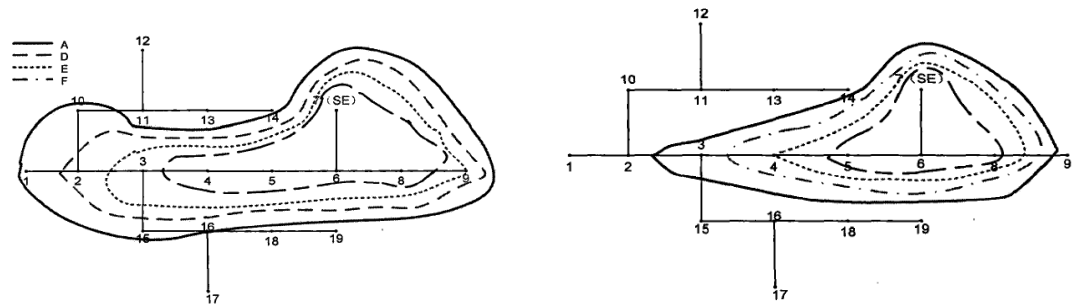

Photo 9 Sag region (PV control) when sag threshold value is 0.70P.U. under three phase failure Photo 10 Sag region (PV control) when sag threshold value is 0.70 P.U. under single-phase shortcircuit ground failure

\section{Conclusions}

Specific to the study for the distributed power supply contained voltage sag region of the power distribution network, it can help to properly deploy the distributed power supply. Distributed power supply connected network changed the structure of the traditional power distribution network, it offered the model of distributed power supply contained power distribution network voltage sag and put forwarded the calculation method of distributed power supply contained voltage sag. The followings can be obtained:

(1) The photovoltaic power station connection effectively relieves the severity of the voltage sag. The voltage sag amplitude will reduce on the contrary when the temperature going up. The voltage sag amplitude will increase when the illumination intensity going up.

(2) The bigger the distributed power supply capacity, the smaller the voltage sag region, the shorter the duration time, therefore, increase in the capacity of the distributed power supply effectively relieves the voltage sag issue.

(3) When power distribution network occurring failures, the sag region of the connected several equivalent capacity's distributed power supply at different nodes is smaller than the connected at only one node with the same whole capacity's distributed power supply, therefore, the capacity and quantity of the distributed power supply should be reasonably chosen when conducting the deployment of the distributed power supply.

\section{References}

[1] Xiao Xiangning. New Concept of the Active(active) Smart Power Distribution Network [J].Searle Electric Energy Quality,2011,22(9):32-35

[2] Zhang Zhizhe, Li Xingyuan, Cheng Shijie. Framework, Function and Realizaton of the Smart Power Unity Information System [J],Proceedings of the CSEE,2012,30(34):1-7

[3] Zhang Wenliang, Liu Zhuangzhi, Wang Mingjun etc.Research Progress and Development Tendency of the Smart Power Network [J].Power Network,2009,33(13): 1-11

[4] Chen Rui. Voltage Sag Region Analysis of One Power Distribution Network[J].Electrician and Electric Energy Technology,2007,26(3): 73-80

[5] Chang Xuefei. One Calculation Method of Accurate Determination of Voltage Sag Region [J].Electric Power Automation Device,2011,31(4): 64-68

[6] Chen Tiemin, Yang Honggeng. Voltage Sag Evaluation on the Basis of the Modified Failed Points [J]. Electric Power Automation Device,2008,28(6): 66-69 
[7] Chang Xuefei. Voltage Sag Analysis Method Study Caused by Electric Power System Failures [D].Jilan: Electrical Engineering Academy, Shandong University,2010..

[8] Zhang Xuemeng. Study for Location of Voltage Sag Source and Sag Economy [D].North China Electric Power University (Beijing),2010.

[9] ] Xu Qingshan. Distributed Electricity Generation and Microgrid Network Technology

[M].Beijing:Posts and Telecom Press,2011,11.

[10] Chang Xuefei, Tian Lijun, Qin Yinglin. One Calculation Method of Accurate Determination of Voltage Sag Region [J].Electric Power Automation Device,2011,31(4): 64-68 